$\xi=$

\title{
Anticancer prospection of salicin, a historical origin of aspirin
}

\author{
Muhammad Torequl Islam ${ }^{1,2 *}$, Rafael Caetano Magalhães Dantas ${ }^{2}$ \\ ${ }^{1}$ Department of Pharmacy, Southern University Bangladesh, Mehedibag (Chittagong)-4000, Bangladesh \\ ${ }^{2}$ Postgraduate Program in Pharmaceutical Science, Federal University of Piaui, Teresina (Piaui)-64.049-550, Brazil \\ *Corresponding author E-mail: rbiotufpi.br@gmail.com
}

\begin{abstract}
Salicin (an alcoholic $\beta$-glucoside), the historical origin of aspirin. It is chemically related to aspirin and tastes bitter like quinine and evident for a number of important biological activities. The human bitter taste receptor TAS2R16 (hTAS2R16) responds to $\beta$-glucosides such as salicin. Thus, a modulator effect on this receptor may link to salicin-induced anticancer effect. Moreover, it may act by reducing oxidative stress and inflammatory reactions. Among a number of anticancer cellular and molecular mechanisms, salicin is evident to act through suppressing the angiogenic activity in cancer cells. Salicin may be one of the important anticancer drugs. However, the research on this willow plant derived compound is not sufficient, especially in the context of anticancer drug investigation.
\end{abstract}

Keywords: Cancer; Chemoprevention; Salicin.

\section{Introduction}

Salicin (Figure 1), an alcoholic $\beta$-glucoside is produced in (and named after) willow (Salix) barked. It is also found under the bark of Populus spp. and castoreum. Evidence suggests that it has antibacterial (Thomason et al., 2004), pain, headache (Wölfle et al., 2015), anti-inflammatory (Rudeekulthamrong and Kaulpiboon, 2016), analgesic, antipyretic (Pincock, 2005), thrombolytic (Jedinák et al., 2006), and neuro protective activity (Yang et al., 2013). It is structurally similar to aspirin and restricted to the patients having asthma, diabetes, gout, gastritis, hemophilia, stomach ulcers as well as children under 16 , and pregnant and breastfeeding women.

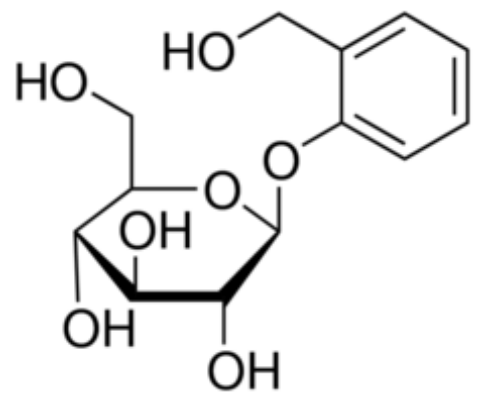

Fig. 1: Salicin [2-(Hydroxymethyl) Phenyl-B-D-Glucopyranoside].

Cancer, a disorder of cell proliferation may lead to tumor production, and it is still an uncontrolled disease and a major cause of death worldwide. Chemotherapy, among the others is a popular therapeutic approach to cancer treatment. Findings on willow tree (Salix spp.), especially on salicin suggest that it can be used for the treatment and prevention of cancer. Theis writing aims to sketch a current scenario of anticancer potential of salicin.

\section{Anticancer aspects of salicin}

The crude water extracts of the young leaves of $S$. safsaf exerted a cytotoxic effect on the acute myeloid leukemia (El-Shemy et al., 2003). This extract was also evident to act against human carcinoma cells (in vivo and in vitro). The authors suggested possible mechanisms may include - apoptotic cell death, DNA damage, and cell membrane rupture and/or protein denaturation (El-Shemy et al., 2007). In a study, salicin isolated from the willow bark extracts inhibited the cell growth and promotes apoptosis in human colon (HT 29 and HCT 116) and lung cancer (A 549 and SW2) cell lines, irrespective of their cyclooxygenase (COX)-selectivity (Hostanska et al., 2007). However, the water extract of willow bark also showed an anti-proliferative effect on colon-carcinoma cell line HT-29, where an increased COX-1 and COX-2 mRNA expressions was also observed (Bonaterra et al., 2010).

Inflammation frequently accompanies the progress of cancer, especially the colorectal cancer (CRC). In a study, the ethanolic extract of the S. aegyptiaca (a Salix species), which was rich in salicin, catechin. Catechol strongly reduced the proliferation of HCT-116 and HT29 CRC cells, possibly via cell cycle arrest at G1/S independent of DNA damage, induction of apoptosis through a p53 dependent pathway and an inhibition of phosphoinositide 3-kinase (PI3K)/protein kinase B (Akt) and mitogenactivated protein kinase (MAPK) pathways (Enayat et al., 2013). The ethanolic extract was also evident to amplify apoptosis of neoplastic cells within the colon mucosa of the 1, 2-dimethyl hydrazine (DMH)-treated mice along with the lowering of the levels of epidermal growth factor receptor (EGFR), nuclear $\beta$-catenin, and COX-2 in colon cancer cell lines HT-29 and HCT-116, suggesting a potential source of the chemo preventive agent (Bounaama et al., 2016).

The extract of Willow's bark is also evident to exert an antioxidative effect in the human umbilical vein endothelial cells (HUVECs) and Caenorhabditis elegans (Ishikado et al., 2013), where the extract prevented oxidative-stress-induced cytotoxicity by 
increasing mRNA and protein expression levels of the nuclear factor erythroid 2-related factor 2 (Nrf2) target genes heme oxygenase-1, $\gamma$-glutamylcysteine ligase modifier and catalytic subunits, and p62 and intracellular glutathione (GSH) in HUVECs, gcs-1::green fluorescent protein reporter (a target of the Nrf2 ortholog SKN-1) in HUVECs and death of C. elegans. In another study, salicin induced in SH-SY5Y cells phosphorylation of extracellular-signal-regulated kinase (ERK) and cyclic AMPresponsive element-binding protein 1 (CREB), the key transcription factors of neuronal differentiation, suggesting a modulatory effect on neurite outgrowth by bitter taste receptor activation (Wölfle et al., 2015). Salicin derivatives, namely saliglandin and 6'-O-(Z)-p-coumaroylsalicin 14 another fourteen analogues isolated from the twigs of $S$. glandulosa decreased nitric oxide (NO) synthesis in lipopolysaccharide (LPS)-activated microglial cell (BV-2). Moreover, one of them was found to increase the nerve growth factor (NGF) production in C6 glioma cells, suggesting the salicin derivatives having potent anti-neuroinflammatory effects (Kim et al., 2015).

Salicin is evident to exert an anticancer effect on Ehrlich's ascites carcinoma (EAC) (in vivo), human breast cancer (MCF7 cell line, in vitro) and the pancreatic cancer cell line (Panc-1, in vitro) by decreasing in tumor weight, tumor volume, the carcinoembryonic antigen (CEA) level, and reduced tumor cholesterol content through an antioxidant (reduced malondialdehyde level and increased GSH and catalase content) and an anti-inflammatory activity (reduced tumor necrosis factor alpha $(\mathrm{TNF}-\propto)$ level) in vivo, while activation of caspase 3/7 apoptotic pathway in in vitro models (Sabaa et al., 2017).

Angiogenesis is an essential process for tumor progression, thus, negative regulation of this process may be a helpful strategy for antitumor therapy. In a study, salicin was found to suppress the angiogenic activity on endothelial cells, such as migration, tube formation, and sprouting from an aorta. Additionally, it reduced reactive oxygen species (ROS) production and activation of the extracellular signal-regulated kinase pathway (Kong et al., 2014).

\section{Conclusion}

In summary, the antioxidant and anti-inflammatory activities, especially the ROS scavenging and induction capability of physiological antioxidants in the first case, while inhibitory of proand/or inflammatory mediators in the second case may link with its anticancer potential. Moreover, salicin can act through the bitter taste receptor as well as a number cellular and molecular pathways as an anticancer candidate. Salicin as well as the willow bark may be one of the potential sources of anticancer drugs. More research is required on salicin's anticancer effects.

\section{Conflicts of interest}

None declared.

\section{References}

[1] Bonaterra GA, Kelber O, Weiser D, Metz J, Kinscherf R. In vitro anti-proliferative effects of the willow bark extract STW 33-I. Arzneimittelforschung 2010; 60:330-335. https://doi.org/10.1055/s0031-1296296.

[2] Bounaama A, Enayat S, Ceyhan MS, Moulahoum H, Djerdjouri B, Banerjee S. Ethanolic Extract of Bark from Salix aegyptiaca Ameliorates 1,2-dimethylhydrazine-induced Colon Carcinogenesis in Mice by Reducing Oxidative Stress. Nutr Cancer 2016; 68:495-506. https://doi.org/10.1080/01635581.2016.1152379.

[3] El-Shemy HA, Aboul-Enein AM, Aboul-Enein KM, Fujita K. Willow leaves' extracts contain anti-tumor agents effective agains three cell types. PLoS One 2007; 2:e178. https://doi.org/10.1371/journal.pone.0000178.

[4] El-Shemy HA, Aboul-Enein AM, Aboul-Enein MI, Issa SI, Fujita $\mathrm{K}$. The effect of willow leaf extracts on human leukemic cells in vitro. J Biochem Mol Biol 2003; 36:387-389. https://doi.org/10.5483/BMBRep.2003.36.4.387.

[5] Enayat S, Ceyhan MŞ, Başaran AA, Gürsel M, Banerjee S. Anticarcinogenic effects of the ethanolic extract of Salix aegyptiaca in colon cancer cells: involvement of Akt/PKB and MAPK pathways.
Nutr
Cancer
2013 ;
65:1045-1058. https://doi.org/10.1080/01635581.2013.850966.

[6] Hostanska K, Jürgenliemk G, Abel G, Nahrstedt A, Saller R. Willow bark extract (BNO1455) and its fractions suppress growth and induce apoptosis in human colon and lung cancer cells. Cancer De-
tect
Prev
2007
31:129-139. https://doi.org/10.1016/j.cdp.2007.03.001

[7] Ishikado, Sono Y, Matsumoto M, Robida-Stubbs S, Okuno A, Goto M, King GL, Blackwell TK, Makino T. Willow bark extract increases antioxidant enzymes and reduces oxidative stress through activation of Nrf2 in vascular endothelial cells and Caenorhabditis elegans. Free Radic Biol Med 2013; 65:1506-1515. https://doi.org/10.1016/j.freeradbiomed.2012.12.006.

[8] Jedinák A, Maliar T, Grancai D, Nagy M. Inhibition activities of natural products on serine proteases. Phytother Res 2006; 20:214217. https://doi.org/10.1002/ptr.1836.

[9] Kim CS, Subedi L, Park KJ, Kim SY, Choi SU, Kim KH, Lee KR. Salicin derivatives from Salix glandulosa and their biological activities. Fitoterapia 2015 https://doi.org/10.1016/j.fitote.2015.08.013

[10] Kong CS, Kim KH, Choi JS, Kim JE, Park C, Jeong JW. Salicin, an extract from white willow bark, inhibits angiogenesis by blocking the ROS-ERK pathways. Phytother Res 2014; 28:1246-1251. https://doi.org/10.1002/ptr.5126.

[11] Rudeekulthamrong P, Kaulpiboon J. Application of amylomaltase for the synthesis of salicin- $\alpha$-glucosides as efficient anticoagulant and anti-inflammatory agents. Carbohydr Res 2016; 432:55-61. https://doi.org/10.1016/j.carres.2016.06.011.

[12] Sabaa M, ELFayoumi HM, Elshazly S, Youns M, Barakat W. Anticancer activity of salicin and fenofibrate. Naunyn Schmiedebergs Arch Pharmacol 2017. https://doi.org/10.1007/s00210-017-1407-y.

[13] Pincock S. The quest for pain relief: how much have we improved on the past? 2005. The Scientist 2005; p. S30+.

[14] Thomason LC, Court DL, Datta AR, Khanna R, Rosner JL. Identification of the Escherichia coli K-12 ybhE gene as pgl, encoding 6phosphogluconolactonase. J Bacteriol 2004; 186:8248-8253. https://doi.org/10.1128/JB.186.24.8248-8253.2004.

[15] Wölfle U, Haarhaus B, Kersten A, Fiebich B, Hug MJ, Schempp CM. Salicin from Willow Bark can Modulate Neurite Outgrowth in Human Neuroblastoma SH-SY5Y Cells. Phytother Res 2015; 29:1494-1500. https://doi.org/10.1002/ptr.5400.

[16] Yang H, Lee SH, Sung SH, Kim J, Kim YC. Neuroprotective compounds from Salix pseudo-lasiogyne twigs and their anti-amnesic effects on scopolamine-induced memory deficit in mice. Planta Med 2013; 79:78-82. https://doi.org/10.1055/s-0032-1327949. 